\title{
Vertical dimension rehabilitation in a patient with a few remaining severely worn teeth using partial removable denture prosthesis
}

\author{
Sua Jung, Min-Ji Kim, Hong-So Yang, Kwi-Dug Yun, Chan Park, and Sang-Won Park* \\ Department of Prosthodontics, School of Dentistry, Chonnam National University, Gwangju 61186, Republic of Korea
}

(Received Oct 11, 2017; Revised version received Oct 25, 2017; Accepted Nov 10, 2017)

\begin{abstract}
Tooth wear is loss of surface of teeth, and may be classified into physiological and pathologic wear. When tooth wear is accelerated excessively, it is pathologic tooth wear. Pathologic tooth wear may result in many problems including decrease of occlusal vertical dimension, as well as unacceptable damage to anterior guidance. In this study, the patient had loss of posterior teeth and anterior severely worn dentition. Vertical dimension analysis was conducted and $3 \mathrm{~mm}$ increase of vertical dimension was determined. After 8 weeks of stabilization period with temporary prostheses, definitive restoration with fixed dental prosthesis and partial removable denture prosthesis were accomplished and satisfactory outcomes were achieved in functional and esthetic aspects.
\end{abstract}

KEY WORDS: Partial removable denture prosthesis, Vertical dimension, Worn dentition

\section{서 론}

치아 마모는 치아 표면의 소실을 의미하는 일반적인 용어로 생리적 마모와 병적 마모로 구분할 수 있다. 생 리적인 마모는 연령의 증가와 함께 나타나는 정상적인 과정으로, 보통은 그 양이 적어 정상적인 현상으로 간주 한다 $[1,2]$. 하지만 이러한 마모가 가속화되어 병적인 변 화를 일으키면 교합면 손상과 치수 병변이 나타날 수 있 고, 수직 교합 고경의 감소와 더불어 교합 평면의 붕괴 를 초래하며, 저작 효율의 감소와 함께 전방 유도를 위 해 필요한 전치 형태를 파괴하여 심미적인 문제점을 야 기할 수 있다[3].

심한 마모를 보이는 환자에서 우선적으로 고려해야 할 것은 수직 교합 고경의 상실 유무에 대한 판단이다. 수직 고경(vertical dimension)이란 악간 거리를 의미하며, 하악이 중심 위에 있을 때 치아 끼리 접촉하는 수직 교 합 고경(vertical of occlusion)과 하악이 생리적인 안정위 에 있을 때 치아의 접촉이 없는 안정위 수직 고경(rest

*Corresponding author: Sang-Won Park

Department of Prosthodontics, School of Dentistry, Chonnam National University, 33 Yongbong-ro, Buk-gu, Gwangju 61186, Republic of Korea Tel.: +82-62-530-5631, Fax: +82-62-530-5639

E-mail: psw320@jnu.ac.kr vertical dimension)으로 나눌 수 있다[4].

교합이 붕괴된 환자에서 새로운 수직 교합 고경의 설 정은 환자의 적절한 심미적, 기능적 회복을 위한 중요한 요소이다. 마모와 치아 상실 등으로 수직 교합 고경의 감소가 의심되는 환자의 보철 수복 시 우선 수직 교합 고경의 감소 유무를 확인하고 수직 교합 고경의 거상량 을 결정하는 것이 필요하다[5].

수직 교합 고경을 결정하는 방법에는 안면 계측법, 발 음 이용법, 연하 기능 이용법, 하악 안정위 이용법, 통계 적 치아 형태 이용법, 측방 두부 방사선 사진 분석법, 환 자의 감각 이용법, 근전도 이용법 등이 있다[6]. 정확한 수직 교합 고경 결정을 위해서는 여러 가지 방법을 이 용해 다양한 측면에서 평가가 필요하며, 수직 교합 고경 증가 시에는 임시 보철물을 통한 장기간의 관찰로 환자 의 순응도를 평가해야 한다[5].

본 증례는 마모로 인해 수직 교합 고경이 감소된 환자 에서 다양한 방법을 이용하여 환자의 상태를 평가하고, 진단 납형을 제작하여 환자가 적응 가능한 수직 교합 고 경을 새롭게 설정하였다. 이후 8 주 동안 임시 보철물과 임시 국소의치를 사용하면서 기능, 심미, 발음과 환자의 적응 여부를 확인하였고, 새롭게 설정된 수직 교합 고경 의 적절성 여부를 판단하였다. 이를 참고하여 최종적으 로 고정성 보철물과 상하악 국소의치를 제작하였다. 이 
에 기능적, 심미적으로 만족할 만한 결과를 보였기에 보 고하는 바이다.

\section{증례보교}

본 증례의 환자는 70세 여성으로 위아래 어금니가 없 다는 주소로 내원하였다. 의과적 병력으로는 뇌허혈 발 작, 수축기 심부전, 인슐린 비의존형 당뇨병이 있었으며, 턱관절과 기타 저작근 장애, 이갈이, 이 악물기 등의 비 기능적인 악습관은 없었다.

구강 내 소견으로 상악 좌측 중절치에서 3 도의 동요 도를 보였으며, 다수의 구치부 상실, 잔존치의 심한 교 합면 마모, 측절치와 견치에 비우식성 치경부 병소가 발 견되었다(Fig. 1). 안모 관찰 시 하안모의 길이 감소, 깊 은 비순구, 얇은 입술이 관찰되었다.

방사선학적인 검사에서 상악 좌측 중절치의 치근 파 절과 하악 우측 제 1 대구치의 치주 농양 관찰되었으며 (Fig. 2), 측두 하악 관절 방사선 사진상 턱관절에 기능
적, 해부학적 특이 소견 관찰되지 않았다(Fig. 3).

예후가 불량할 것으로 판단된 상악 좌측 중절치, 하악 우측 제 1 대구치 발거 후 잔존 치아는 고정성 보철물로 수복하고, 상실 부위에 대해서는 국소의치를 제작하는 것으로 계획하였다.

수직 교합 고경의 평가를 위한 분석을 실시하였다. Willis의 안면 계측 방법[7]을 이용하여 안면 분석 시행 한 결과, 하안면 고경이 동공 구각부 간 거리보다 약간 감소되어 있는 것을 확인하였다(Fig. 4A). 상하악 순측

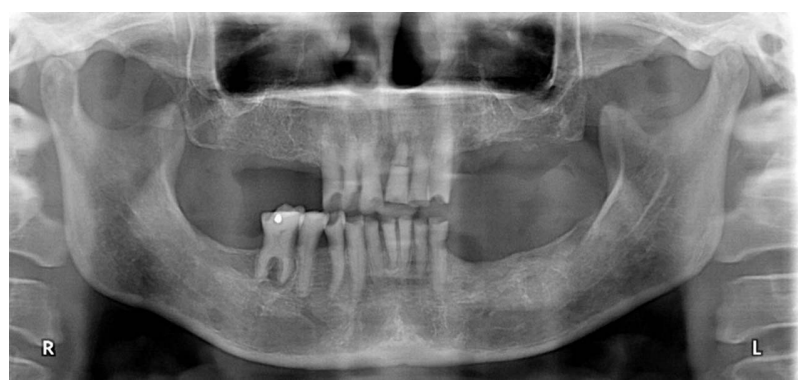

Fig. 2. Panoramic radiograph before treatment.

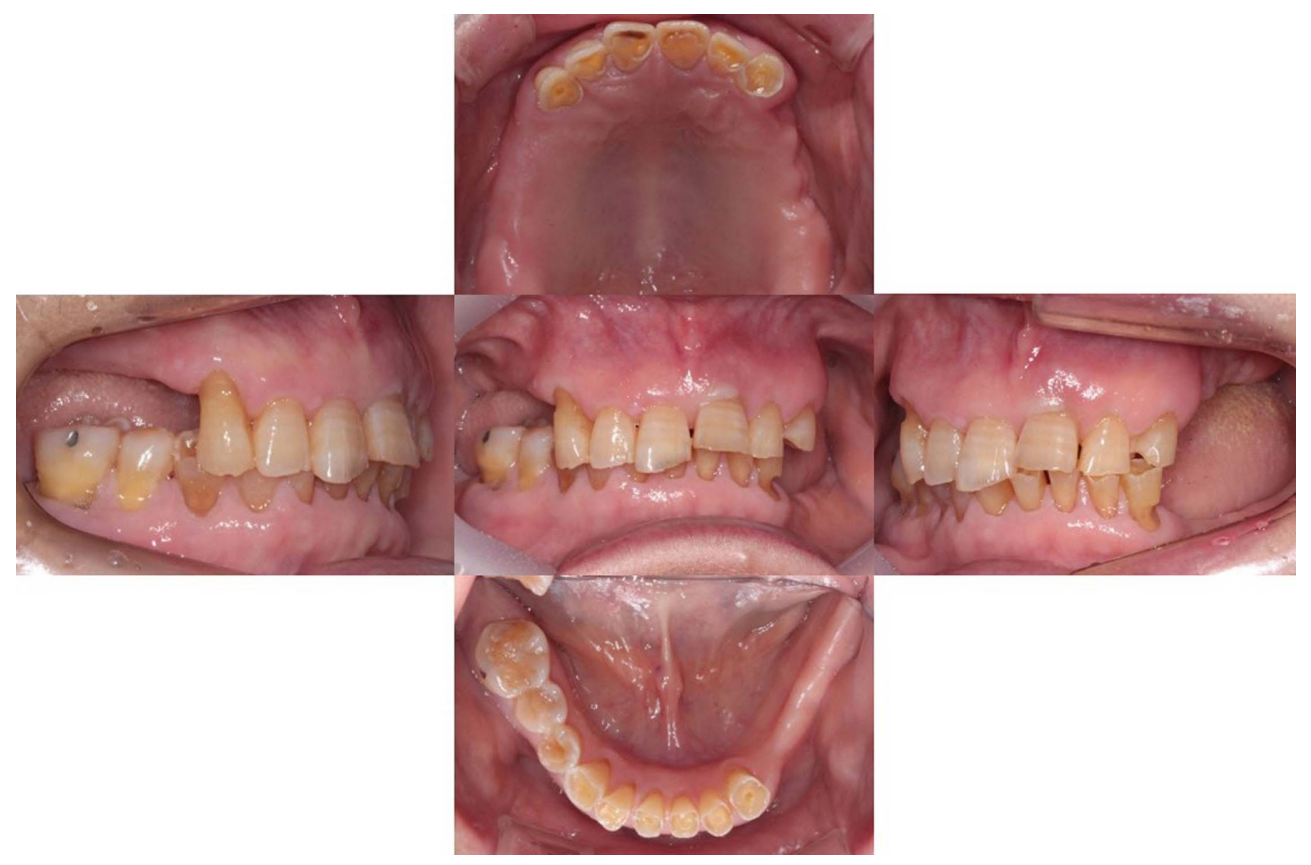

Fig. 1. Intraoral photograph before treatment.
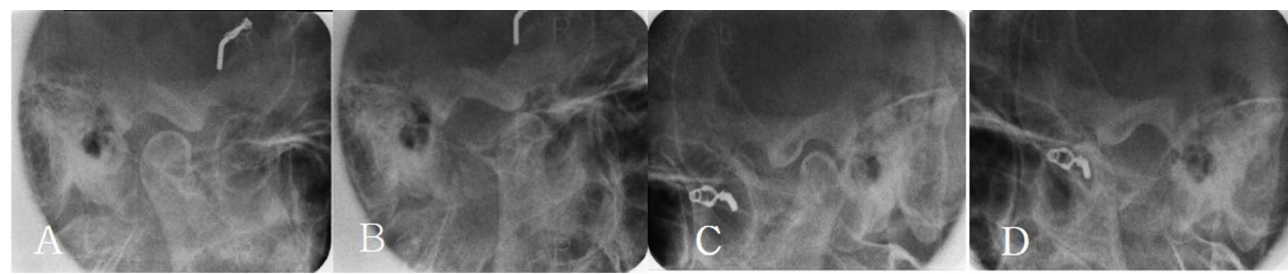

Fig. 3. TMJ series before treatment. (A) Rt. close, (B) Rt. opening, (C) Lt. close, and (D) Lt. opening. 
전정 간 거리는 $35 \mathrm{~mm}$ 로 평균치인 $38-42 \mathrm{~mm}$ 보다 작았 으며(Fig. 4B), 안정위 수직 고경과 수직 교합 고경 간의 차는 $5 \mathrm{~mm}$ 로 평균인 2-4 $\mathrm{mm}$ 보다 크게 나타났으며, "S"발음 평가 시 공극은 $4 \mathrm{~mm}$ 였다. 임상적 치관 길이를 측정하였을 때 상악 중절치는 7-9 mm(Fig. 4C), 하악 중 절치는 6-7 $\mathrm{mm}(\mathrm{Fig} .4 \mathrm{D})$ 로 평균 길이보다 짧아져 있었 고, 잔존 치아의 교합면에서 병적인 마모가 관찰되었다. 이상의 분석 결과를 종합하여 구치부의 상실로 인한 지 지 부족으로 전치부의 심한 마모를 동반한 교합 수직 교 합 고경의 감소로 진단하여 수직 교합 고경을 회복해주 기로 결정하였다. 수직 교합 고경은 정적인 기준이 아니 라, 개인마다 가지고 있는 생리학적 범위로 존재하기 때 문에 상하악 절치 간 $5 \mathrm{~mm}$ 까지 거상하는 것은 선택 가 능한 방법으로 고려된다[6]. 환자의 상하악 순층 전정 간
거리, 안정위 수직 고경과 수직 교합 고경 간의 차이, 최 소 발음 간격 수치를 고려하였을 때 정상으로 회복시켜 주기 위해서는 최소 $3 \mathrm{~mm}$ 의 거상이 필요하기 때문에 본 증례에서는 수직 교합 고경을 $3 \mathrm{~mm}$ 거상하기로 결정하 였다. 안궁 이전 및 고딕 아치 장치를 이용하여 중심위를 채득하여 교합기(PROTAR® evo, Kavo dental $\mathrm{GmbH}$, Biberach, Germany)로 이전하고 진단 납형을 제작하였다 (Fig. 5).

잔존 치아의 지대치 삭제 후 새롭게 설정한 수직 교합 고경에 맞추어 임시보철물과 임시 의치를 제작하였다 (Fig. 6).

임시 보철물 단계에서 8주 동안 변화된 수직 교합 고경 대한 적응을 평가하였다. 환자는 기능적, 심미적으로 만족 해 하였으며, 근육의 피로감, 턱관절 통증, 임시 수복물의

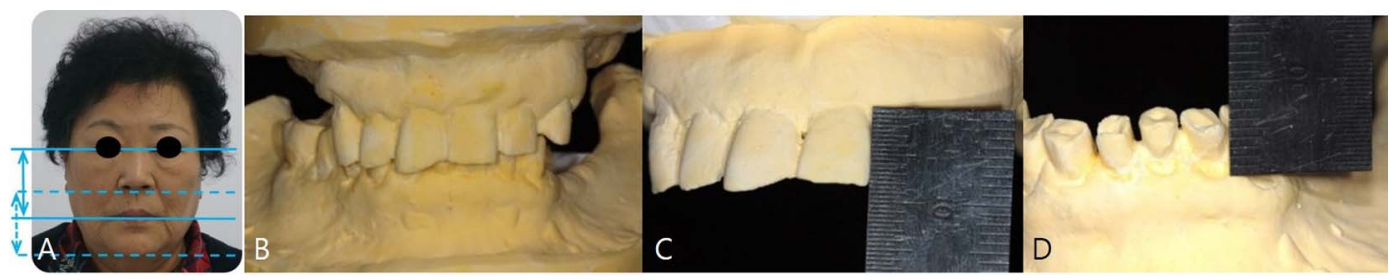

Fig. 4. Vertical dimension evaluation. A : Facial photograph before treatment, B : Intervestibular space (35 mm), C : Clinical crown height of upper central incisor (7 9 mm), D : Clinical crown height of lower central incisor $(6 \sim 7 \mathrm{~mm})$.

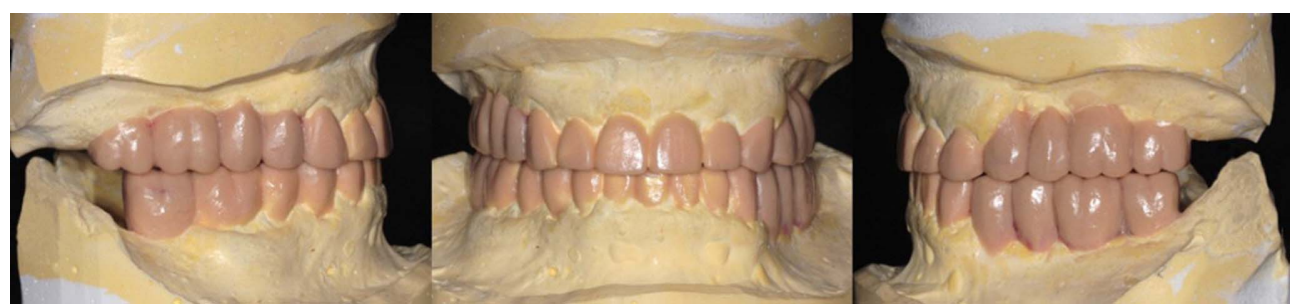

Fig. 5. Diagnostic wax up model.

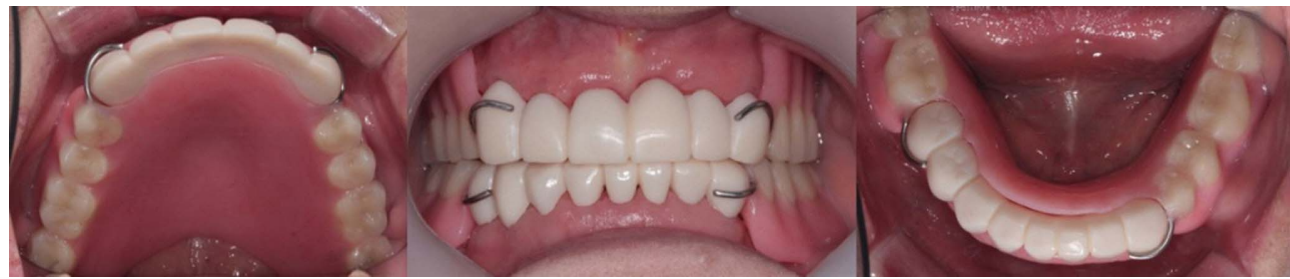

Fig. 6. Provisional restoration.

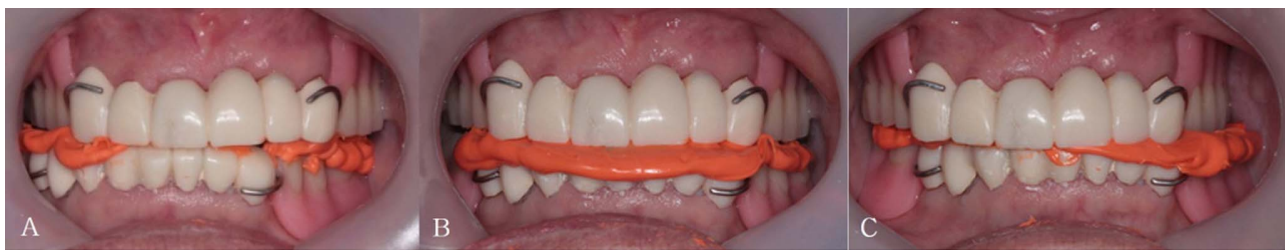

Fig. 7. Check bite registration. (A) Right lateral, (B) Protrusive, and (C) Left lateral. 


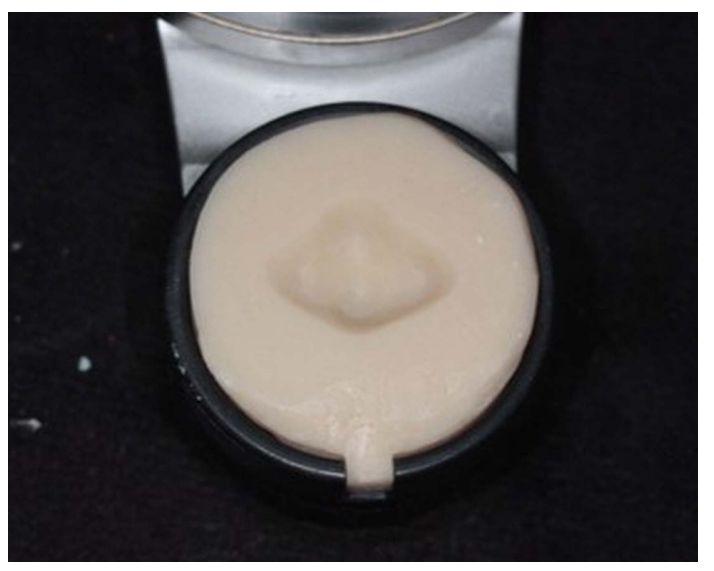

Fig. 8. Customized anterior guidance table.

마모 및 파절 등이 나타나지 않고 불편감 없이 유지되어 폴리비닐 실록산 인상재(Honigum $囚$, DMG Hamburg, Germany)를 이용하여 최종 인상을 채득하였다.

체크바이트를 채득(Fig. 7)하여 전방 및 측방 운동 시의 과로각을 교합기에 반영하였고, 전방 유도판(customized anterior guidance table)을 제작(Fig. 8)하여 임시 수복물 에서의 전방 유도를 재현하고 최종 보철물을 제작하였 다. 상하악의 모든 고정성 보철물은 금속도재관으로 제 작하였으며, 국소의치의 지대치인 상악 전치부와 하악
좌측 견치는 설면 레스트, 하악 우측 제 1,2 소구치는 근 심레스트가 부여된 금속도재관으로 수복하였다(Fig. 9).

최종 고정성 보철물을 완성 후 국소의치의 금속구조 물와 의치상 제작을 위해 개인트레이를 제작하여 모델 링 컴파운드(Peri-compound $囚$, GC Corp., Tokyo, Japan)

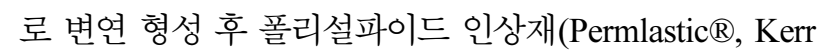
Manufacturing co, Romulus, USA)로 인상 채득하였고, 작업 모형을 제작하여 의치의 금속구조물을 제작하였다. 금속구조물 상에 교합제를 제작하여 양손 조작법을 이 용해 악간교합관계를 채득하여 반조절성 교합기에 마운 팅 한 후 국소의치를 제작하였다(Fig. 10). 최종 보철물 수복 후 측두 하악 관절 방사선 사진에서 안정적인 과 두 위치를 확인하였다(Fig. 11).

환자는 최종 보철물에 기능적, 심미적으로 만족하였고, 1년이 지난 현재까지 특별한 문제가 발견되지 않아 정 기적으로 내원하여 검사 시행 중이다.

\section{교 찰}

심한 마모를 보이는 환자의 치료에서 우선적으로 고 려해야할 것은 마모의 원인을 파악하고 수직 교합 고경

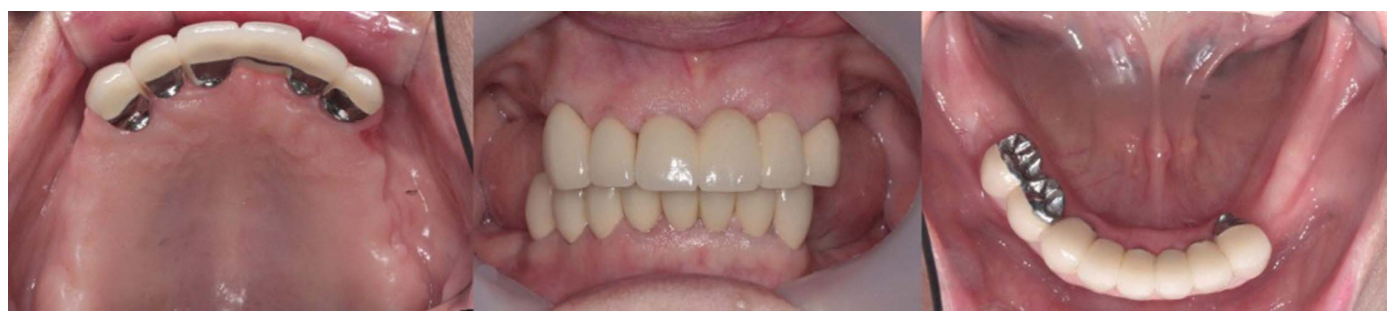

Fig. 9. Surveyed crown.

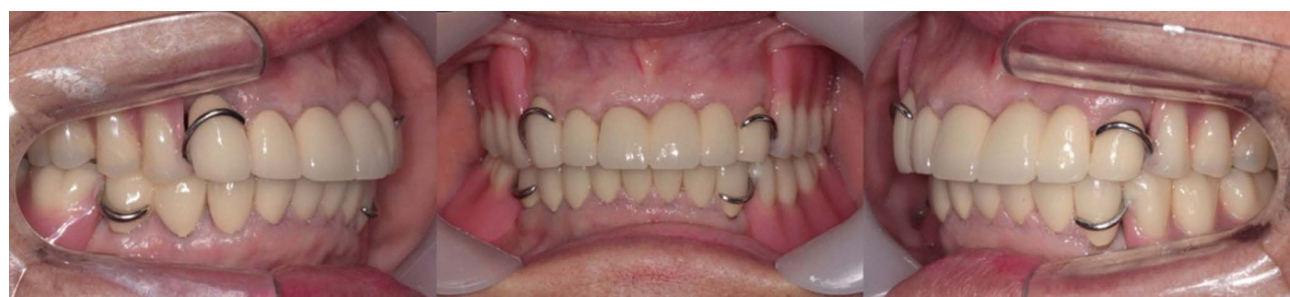

Fig. 10. Definitive prosthesis.

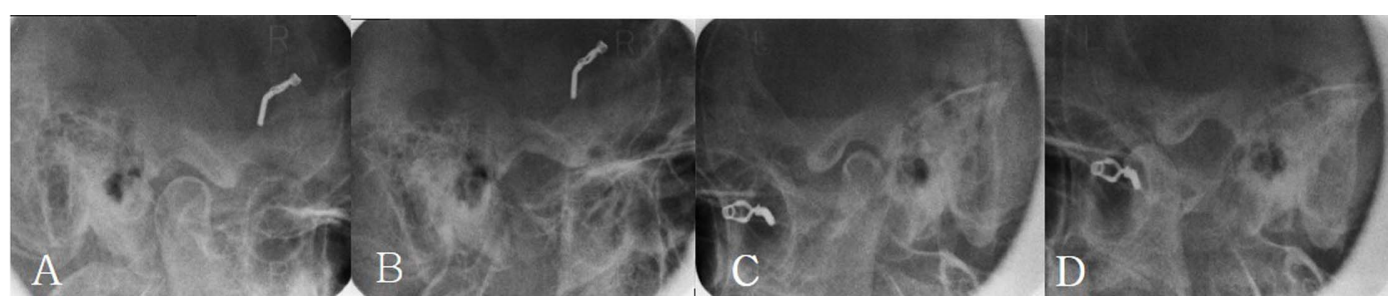

Fig. 11. TMJ series after treatment. (A) Rt. close, (B) Rt. opening, (C) Lt. close, and (D) Lt. opening. 
Sua Jung et al.

의 소실 유무를 판단하여, 현재 상태의 회복과 장기간의 안정성을 확보하는 것이다[8].

심한 마모 환자에서 수직 교합 고경의 감소 여부는 논 란이 되어 왔다. Briggs와Bishop은 수직 교합 고경의 감 소가 발생한 경우 수직 교합 고경의 거상을 통해 보철 적으로 회복해야 한다고 주장하였으며[9] Dawson, Dahl 과 Krogstad는 치아 맹출, 치조골의 보상 성장으로 인하 여 수직 교합 고경이 유지된다고 주장하였다 $[1,10]$.

수직 교합 고경을 결정하는 방법에는 안면 계측법, 발 음 이용법, 연하 기능 이용법, 하악 안정위 이용법, 통계 적 치아 형태 이용법, 측방 두부 방사선 사진 분석법, 환 자의 감각 이용법, 근전도 이용법 등이 있다[6]. 이러한 다양한 평가 방법들은 모두 유용하지만, 한 가지 방법만 으로는 정확한 평가를 하기 어렵다. 따라서 정확한 수직 교합 고경 결정을 위해서는 여러 가지 방법을 이용해 다 양한 측면에서 평가가 필요하며, 수직 교합 고경 증가 시에는 임시 보철물을 통한 평가 기간이 요구된다[5]. 임 시 보철물을 장착하여 평가하는 기간에 대해서, Abduo 와 Lyons는 수직 교합 고경을 거상하였을 때 나타나는 증상은 자기 제한적이고 2 주 이내에 해소되는 경향을 보인다고 하였고[6], Gross와 Ormianer는 4주 경과 관찰 후 증상이 없으면 최종 보철물을 고려할 수 있다고 하 였다[11].

본 증례의 환자는 구치부 상실과 전치부 교합면의 마 모가 관찰되었으며, 수직 교합 고경 상실이 의심되어 평 가를 실시하였다. 다양한 방법들을 이용하여 분석들 시 행한 결과 수직 교합 고경의 감소를 확인하였으며, 수직 교합 고경의 회복이 필요하다고 판단하였다. 환자의 중 심위 상태에서 수직 교합 고경을 $3 \mathrm{~mm}$ 증가시키기로 결정하였고, 지대치 삭제 후 임시 보철물과 임시 의치를 제작하였다.

본 증례에서는 회복된 수직 교합 고경의 임시 보철물 을 8 주 간 사용하면서 기능, 심미, 환자의 적응도를 평 가함으로써 회복된 수직 교합 고경의 적절성 여부를 판 단하였다. 이를 참고하여 최종적으로 다수의 잔존 치아 는 고정성 보철물로 수복하였고, 상하악 국소의치를 제 작하였다.

\section{결 론}

마모를 보이는 환자의 치료에서 우선적으로 고려해야 할 것은 마모의 원인과 수직 교합 고경의 변화 유무에 대한 판단이다. 본 증례의 환자는 구치부의 상실과 잔존
치아의 교모로 인해 수직 교합 고경의 감소가 발생하였 으며, 다양한 진단 과정과 진단 납형 제작을 통해 최소 한의 교합 거상량을 결정하였고, 8 주의 임시 보철물 안정 화 기간 동안 기능, 심미, 환자의 적응도를 평가함으로써 회복된 수직 교합 고경의 적절성 여부를 판단하였다.

이를 참고하여 최종적으로 다수의 잔존 치아는 고정 성 보철물로 수복하였으며, 상하악 국소의치를 제작하 였다. 최종 보철물 장착 후 약 1 년여의 추적 관찰 결과 심미적, 기능적으로 만족스러운 결과를 얻었다.

\section{Conflict of Interest}

The authors declare that they have no competing interests.

\section{ORCID}

$\begin{array}{ll}\text { Sua Jung } & 0000-0001-6728-0295 \\ \text { Min-Ji Kim } & 0000-0002-3241-5214 \\ \text { Hong-So Yang } & 0000-0002-6047-9733 \\ \text { Kwi-Dug Yun } & 0000-0002-2965-3967 \\ \text { Chan Park } & 0000-0000-5729-5127 \\ \text { Sang-Won Park } & 0000-0002-9376-9104\end{array}$

\section{References}

1. Dawson PE. Functional Occlusion-E-Book: From TMJ to Smile Design. 2006: Elsevier Health Sciences.

2. Lerner J. A systematic approach to full-mouth reconstruction of the severely worn dentition. Pract Proced Aesthet Dent 2008;20:81-87.

3. Hattab FN, Yassin OM. Etiology and diagnosis of tooth wear: a literature review and presentation of selected cases. Int J Prosthodont 2000;13:101-107.

4. Fayz F, Eslami A. Determination of occlusal vertical dimension: a literature review. J Prosthet Dent 1988;59: 321-323.

5. Rivera-Morales WC, Mohl ND. Restoration of the vertical dimension of occlusion in the severely worn dentition. Dent Clin North Am 1992;36:651-664.

6. Abduo J, Lyons K. Clinical considerations for increasing occlusal vertical dimension: a review. Aust Dent J 2012; 57:2-10. doi: 10.1111/j.1834-7819.2011.01640.x.

7. Willis FM. Features of the face involved in full denture prosthesis. Dent Cosmos 1935;77:851-854. 
8. Turner KA, Missirlian DM. Restoration of the extremely worn dentition. Prosthet Dent 1984;52:467-474.

9. Briggs P, Bishop K. Fixed prostheses in the treatment of tooth wear. Eur J Prosthodont Restor Dent 1997;5:175180.

10. Dahl BL, Krogstad O. The effect of a partial bite-raising splint on the inclination of upper and lower front teeth. Acta Odontol Scand 1983;41:311-314.

11. Gross MD, Ormianer Z. A preliminary study on the effect of occlusal vertical dimension increase on mandibular postural rest position. Int J Prosthodont 1994;7:216-226. 